\title{
aniki
}

Revista Portuguesa da Imagem em Movimento

Portuguese Journal of the Moving Image

\section{Territórios Femininos por Explorar no Mapa do Cinema Português Contemporâneo}

\section{Ana Sofia Pereira}

IFILNOVA - Instituto de Filosofia da Nova, Faculdade de Ciências Sociais e Humanas, Universidade Nova de Lisboa

pereira.anas@gmail.com

https://orcid.org/0000-0003-1829-0205

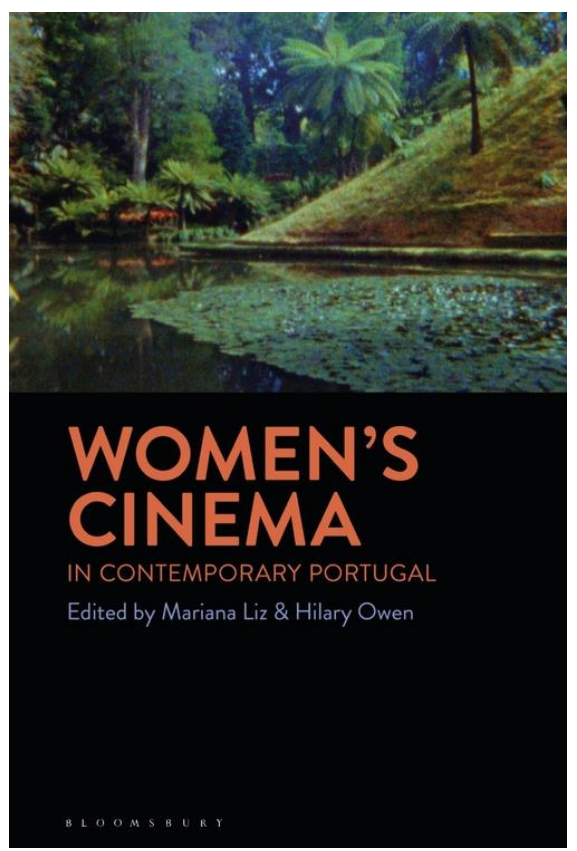

\author{
Liz, Mariana, e Hilary Owen (ed.) \\ 2020. Women's Cinema in \\ Contemporary Portugal. Nova \\ Iorque: Bloomsbury Academic, 288 \\ pp. ISBN: HB: 978-1-5013-4972-0.
}

Em 1949, Simone de Beauvoir, no seu livro seminal O Segundo Sexo, escrevia que falar de mulheres, particularmente por mulheres, era um tema irritante, ultrapassado, mas impossível de ignorar (p. 14). Em 1991, Michèle Le Doeuff referia igualmente que falar da questão feminina, tema insignificante e irritante, era inevitável já que forças formidáveis e cruéis se levantavam contra a integração das mulheres, no caso, no campo da filosofia (p. 6). Estas forças formidáveis contra a integração da mulher em todos os polos da vida humana e artística parecem continuar a existir hoje (de forma mais ou menos declarada), revelando a importância de publicações como Women's Cinema in Contemporary Portugal. 
Em Portugal só muito recentemente, em 2014, através da tese de doutoramento de Ana Catarina Pereira ${ }^{1}$, a questão da presença feminina no cinema português começou a ser aflorada. Embora outros projetos de investigação tenham contribuído para alimentar o estudo da cinematografia nacional no feminino, o livro de Mariana Liz e Hilary Owen vem ocupar um lugar em falta no estudo do cinema português, oferecendo-nos um território (como as próprias autoras indicam) por explorar: a história do cinema feito por mulheres em Portugal.

Fruto de uma excelente colaboração entre as duas editoras e compiladoras da obra, e contando com um leque de autoras com áreas de interesse e atuação que vão desde o cinema português, ao europeu, ibérico, luso-africano, de minorias e de mulheres, esta súmula de relatos procura consolidar um território de estudo para o cinema feito por mulheres, legitimando as suas obras como objetos de análise textual e conceptual (Liz e Owen, 2020, p. 22).

A exploração deste novo território cinematográfico feminino começa na "Introdução", com a apresentação das cineastas a serem estudadas enquanto protagonistas desta viagem. São estas, as suas histórias de vida, o seu trabalho, nas palavras das autoras, que nos instigam a questionar o que sabemos sobre o cinema nacional, o cinema feito por mulheres, o cinema mundial, o cinema de minorias e o cinema transnacional, que nos mostram que o cinema feito em países pequenos, semiperiféricos e por mulheres pode contribuir para a construção de novas conceções de espaço - o espaço atribuído a mulheres e minorias que pode ser expandido ao resto da população - e de tempo que se multiplica e reconfigura - tempo da memória, do arquivo, da contemporaneidade (p. 20). 0 remapeamento do cinema nacional inclusivo da figura feminina que é conseguido nesta publicação tem, porém, uma fragilidade apontada pelas autoras: as mulheres estudadas nesta publicação são de classe média, brancas e heterossexuais. Há, pois, grupos de mulheres e minorias que continuam a permanecer na sombra, que carecem ainda de um estudo mais diverso do cinema português, reforçando a importância da existência de livros como este.

\footnotetext{
${ }^{1}$ Referimo-nos à dissertação de doutoramento A mulher-cineasta: Da arte pela arte a uma estética da diferenciação, que viria a ser publicada em livro (Pereira 2016). A autora possui outras publicações sobre o tema (ex. Pereira, 2013).
} 
A Introdução apresenta-nos igualmente as 4 Secções que compõem o livro e que nos guiam nesta jornada. Na secção 1, "Histories", o Capítulo 1, "Unfinished: The cinema of Noémia Delgado", de Manuela Penafria, e o Capítulo 2, "Four decades on screen: The fiction films of Margarida Gil", de Ana Isabel Soares, exploram as histórias de vida e identidade autoral de duas cineastas, Noémia Delgado e Margarida Gil. No capítulo de Penafria, o que mais se destaca é não só a análise da obra de Delgado, cujo cinema transcende a realidade sem a eliminar (p. 43), ou o estudo de Máscaras (1976), documentário etnográfico que adapta o livro do antropólogo Benjamim Pereira, Máscaras Portuguesas (1973), consolidando a identidade autoral da cineasta num tipo de cinema que dá novas dimensões interpretativas à observação documental, entre o real e o imaginado; mas também a forma como Penafria põe em relevo os filmes inacabados de Delgado, atribuindo-lhes grande importância na compreensão da sua identidade enquanto realizadora e autora. Segundo Penafria, essa é até a maior contribuição deste capítulo: conhecendo a vida e obra de Delgado, reforçar a necessidade do estudo do seu corpo de trabalho contemplando filmes feitos e filmes pensados, filmes ainda à espera das condições ideais para ganharem forma (p. 57). Ana Isabel Soares, por seu turno, começa por referir os obstáculos encontrados na sua investigação: quer a escassez de massa crítica quanto à obra de Margarida Gil, quer a dificuldade em aceder às obras da cineasta, alertando para um problema premente do panorama nacional e sentido por vários investigadores: a distribuição e o acesso a filmes portugueses, particularmente àqueles feitos por mulheres. Soares opta por levar o leitor numa viagem histórica de análise de sete filmes de Margarida Gil - Relação Fiel e Verdadeira (1987); Rosa Negra (1992); O Anjo da Guarda (1998); Adriana (2005), Perdida Mente (2010); Paixão (2012); $\operatorname{Mar}(2019)$-, atravessando quatro décadas da carreira de Gil e avaliando as questões temáticas encontradas em cada uma das suas obras, acabando por concluir que não só há temáticas recorrentes, como Margarida Gil nunca evitou temas complexos (políticos, sociais ou relativos ao género), mas antes os abraçou com uma estética e um estilo de realização que alia sobriedade e delicadeza a um tom mais leve e humorístico.

A secção 2, "Feminisms" - onde se incluem o Capítulo 3, "Monsters, mutants and maternity: The politics of the posthuman in Teresa Villaverde, Raquel Freire e Solveig Nordlund", por Hilary Owen; o Capítulo 4, "Urban homes and urban families: Teresa Villaverde's Colo and Susana Nobre's Ordinary Time", por Mariana Liz; e o Capítulo 5, "Natural women? Nature and femininity in Noémia Delgado's Masks and Teresa Villaverde's Trance", por Patrícia Vieira -, não só interroga como retrata e ilustra a forma como 
diferentes cineastas têm lidado com temáticas ligadas ao feminismo. Abrindo esta secção, Hilary Owen analisa três filmes de três cineastas distintas - Os Mutantes (1998), de Teresa Villaverde; Rasganço (2001), de Raquel Freire; Aparelho Voador a Baixa Altitude (2002), de Solveig Nordlund - para compreender o papel que tiveram na despenalização do aborto - segundo Owen, o tema que definiu e moldou o feminismo político português na última metade do século (p. 84). De formas distintas, usando géneros e subgéneros cinematográficos raramente explorados no panorama nacional, estas cineastas conseguiram transmitir ideias sobre mulheres, direitos sobre o próprio corpo e biopolítica. Nas palavras da autora, “[a]ll three directors deploy 'other worlds' as landscapes for a new 'posthuman' sexual aesthetic, in order to comment allegorically on the need for dialogue between feminism, socialism and materialism in the abortion debates of the late twentieth century”2 (p. 30). Já Liz, no capítulo 4, aborda duas obras de duas cineastas, Teresa Villaverde (Colo, 2017) e Susana Nobre (Tempo Comum, 2018), que, para além de se debruçarem sobre mulheres, exploram as ideias de maternidade, família e casa nos ambientes urbanos de uma Lisboa durante e após a austeridade. A conjugação e o contraponto dos dois filmes permite-nos, segundo a autora, compreender como as cineastas em questão usam uma "feminist address" 3 , termo que Liz aproveita de Lucy Fischer para ilustrar a tensão existente entre modernidade e tradição, novas e velhas conceções de género, pontos cruciais para percebermos a cultura nacional atual (p. 110). Finalmente, Patrícia Vieira analisa, no capítulo seguinte, ainda outras formas de "feminist address", de morada feminina e urbanidade, com os filmes Máscaras (1978), de Noémia Delgado, e Transe (2006), de Teresa Villaverde. A autora constata que tanto Villaverde como Delgado subvertem a ligação entre o feminino e a natureza para criticar preconceitos relativos ao género e a estruturas sociais patriarcais (p. 30).

A secção 3, "Archives", conta com o Capítulo 6, "Image, historical memory, politics: Margarida Cardoso's Kuxa Kanema and Susana de Sousa Dias's 48”, por Estela Vieira; o Capítulo 7, "Affect and the archival turn: Documentaries by Inês de Medeiros and Susana de Sousa Dias", por Alison Ribeiro de Menezes; e o Capítulo 8, “The essay film and Rita Azevedo Gomes's

\footnotetext{
2 “[a]s três realizadoras implementam 'outros mundos' como cenários para uma nova estética sexual 'póshumana', de forma a fazer um comentário alegórico quanto à necessidade de diálogo entre feminismo, socialismo e materialismo nos debates sobre o aborto do final do século XX" (tradução minha)

3 Termo que talvez pudéssemos traduzir como "abordagem feminista", mas que também significa "morada feminista", ambivalência que não deve passar despercebida.
} 
Correspondences", por Ana Cabral Martins. Esta secção questiona a forma como mulheres realizadoras podem contribuir para a construção de uma nova memória (pessoal, histórica e coletiva) que recupere e reconte momentos políticos e sociais de grande peso na história nacional, reposicionando a mulher nesses espaços e tempos. Estela Vieira, através da análise dos documentários Kuxa Kanema: O Nascimento do Cinema (2003), de Margarida Cardoso, e 48 (2010), de Susana de Sousa Dias, e usando o conselho de Paula Amad (ref. ${ }^{\text {a }}$ ), refere que o material de arquivo não tem de ser usado meramente como prova, mas pode ser recuperado como "contraarquivo", como ferramenta que, mediada pelas cineastas, permite repensar verdades históricas e questionar a ambiguidade da memória e da história através da ambiguidade da imagem em movimento. Também Alison Ribeiro Menezes contempla o uso do arquivo nos documentários Cartas a uma Ditadura (2006), de Inês de Medeiros, e 48 (2010), de Susana Sousa Dias, reforçando a reapropriação deste material de arquivo como forma de revelar e questionar o passado, mas acima de tudo como forma de aproximar o espectador, de criar uma ligação afetiva com ele que nos faz, por momentos "jump [...] in our skins, even if we know we are watching these images in the comfort and safety of an upholstered cinema seat" 4 (p. 193). Ana Cabral Martins, por seu turno, encerra esta secção analisando o filme Correspondências (2016), de Rita Azevedo Gomes, como filmeensaio, cunhando-o como uma obra nos interstícios do género, do espaço e, como a autora indica, do statu quo cinematográfico, o que permite à cineasta a criação de novos territórios ainda não explorados na cinematografia nacional.

Finalmente, a secção 4 "Transnationalisms" fecha o livro com dois capítulos: o Capítulo 9, “Women's cinema, world cinema: Margarida Cardoso's Yvone Kane", por Sally Faulkner, e o Capítulo 10, "Portugal's year zero: Emergent women directors, 2014-17", de Filipa Rosário, fazendo a ponte necessária entre as cineastas portuguesas e o cinema internacional, abrindo espaço para que estas realizadoras ganhem expressão no mundo. Sally Faulkner coloca em diálogo a obra de Margarida Cardoso e a de Lucretia Martel, uma professada fonte de inspiração para aquela cineasta nacional, questionando quer as dificuldades sentidas pelas realizadoras ao longo das suas carreiras, quer as semelhanças encontradas nas suas obras, nomeadamente o uso da ambiguidade como traço autoral. Filipa Rosário, por seu turno, tem a 4 "ficar em sobressalto, mesmo sabendo que estamos a ver estas imagens no conforto e segurança de uma cadeira
de cinema bem almofadada." (tradução minha) 
responsabilidade de encerrar este livro dando voz a quatro mulheres cineastas: Joana Pimenta, Salomé Lamas, Cláudia Varejão e Leonor Teles que, sugere a autora, durante a pós-austeridade e a crise económica se conseguiram afirmar em festivais internacionais com filmes de dimensão transnacional e cosmopolita que revelam as novas oportunidades que estão a surgir para o futuro da cinematografia no feminino em Portugal.

Esta viagem pelas últimas cinco décadas do cinema nacional, tendo como protagonistas mulheres realizadoras que abriram e abrem o caminho para o futuro de um cinema feito por mulheres em Portugal e no mundo, consolida a importância de conhecer este território feito de memórias femininas. De mencionar, contudo, é o facto de, em dez capítulos do livro, haver nomes de cineastas que se repetem: Noémia Delgado (capítulos $1 \mathrm{e}$ 5); Teresa Villaverde (capítulos 3, 4 e 5); Margarida Cardoso (capítulos 6 e 9); Susana de Sousa Dias (capítulos 6 e 7). Se isto nos remete para a importância que estas cineastas têm no panorama nacional e transnacional, justificando o estudo da sua obra sob vários prismas numa mesma publicação, não podemos deixar de questionar: Não haveria outras mulheres cineastas a serem analisadas? Haverá um número tão reduzido de mulheres no cinema nacional que implique tal repetição de nomes? Ou será este mais um sinal que muitas delas continuam a ser invisíveis?

Este questionamento, contudo, não retira importância a este livro, cuja escrita em inglês lhe permitirá ter um carácter transnacional, característica que as autoras pretendem conferir também ao cinema português feito por mulheres. A obra lembra-nos que é importante continuar a questionar, pois, embora a "questão feminina" possa parecer "irritante e ultrapassada" (como afirmavam Beauvoir e Le Doeuff), é importante continuar a descobrir e recuperar os territórios cinematográficos ocupados por mulheres e minorias, continuar a abrir o escopo da investigação e acompanhar a viagem para um futuro que, espera-se, seja mais diverso, inclusivo e transnacional.

\section{Referências}

Beauvoir, Simone de. 2015 [1949]. O Segundo Sexo, vol. 1, trad. Sérgio Milliet. Lisboa: Quetzal Editores.

Le Doeuff, Michèle. 2007 [1991]. Hipparchia's Choice: An Essay Concerning Women, Philosophy, Etc, Trad. Trista Selous. New York: Columbia University Press. 
Pereira, Ana Catarina. 2013. "Mulheres por detrás das câmaras: A ficção de longa-metragem, mediada por um olhar feminino." Em Filmes Falados: Cinema em Português, VJornadas, por Ana Catarina Pereira e Frederico Lopes (ed.), pp. 95-108. Covilhã: Livros LabCom Books.

. 2014. "A Mulher-cineasta: Da arte pela arte a uma estética da diferenciação". Tese de Doutoramento. Covilhã: Universidade da Beira Interior.

. 2016. A Mulher-cineasta: Da arte pela arte a uma estética da diferenciação. Covilhã: LabCom.IFP. 